\title{
The Contribution of Online Resources to Fostering Digital Learning and Effective Teaching
}

\author{
Benigno P. Legamia. Jr., ${ }^{1 *}$, Yuri Walter D. Akiate ${ }^{2}$ \\ ${ }^{1}$ College of Industrial Technology, Don Honorio Ventura State University, Philippines \\ ${ }^{2}$ Graduate School, Don Honorio Ventura State University, Philippines
}

Received August 11, 2020; Revised September 7, 2020; Accepted October 19, 2020

\begin{abstract}
Cite This Paper in the following Citation Styles
(a): [1] Benigno P. Legamia. Jr., Yuri Walter D. Akiate, "The Contribution of Online Resources to Fostering Digital Learning and Effective Teaching," Universal Journal of Educational Research, Vol. 8, No. 11, pp. 5660 - 5669, 2020. DOI: 10.13189/ujer.2020.081170.
\end{abstract}

(b): Benigno P. Legamia. Jr., Yuri Walter D. Akiate (2020). The Contribution of Online Resources to Fostering Digital Learning and Effective Teaching. Universal Journal of Educational Research, 8(11), 5660 - 5669. DOI: 10.13189/ujer.2020.081170.

Copyright $\odot 2020$ by authors, all rights reserved. Authors agree that this article remains permanently open access under the terms of the Creative Commons Attribution License 4.0 International License

\begin{abstract}
Covid-19 has brought about more higher education institutions confronted with the challenge of how to uphold continuity of learning and teaching while at the same time confronting the threat of extended closures. Thus, it is the primary intention of the researchers to determine how these online resources contribute to fostering digital learning and effective teaching in a state university in the Philippines during such unprecedented times. A qualitative method, employing the grounded theory approach was used to achieve this aim. To obtain in-depth information, twenty (20) participants were chosen from different academic units of the university. Ten (10) were faculty members who had been teaching for at least 5 years and ten (10) students who are at least on their second collegiate year level. Based on the themes generated from the statements of the participants, the researchers came up with the emerging concept on how to foster digital learning and effective teaching through online resources. The factors discussed in the paper together with proper utilization of online resources are expected to be addressed and be made available in order to maximize the use of online resources in 2020 and beyond.
\end{abstract}

Keywords Digital Learning and Teaching, Covid-19, Online Resources, Grounded Theory, Educational Units

\section{Introduction}

The abrupt flare-up of a destructive disease Corona
Virus also called Covid-19 shook the whole world. The World Health Organization (WHO) announced it as a pandemic [1]. Avoiding direct contact with people is transcendent at this stage, which will cancel out learning possibilities. The academic organizations are battling to discover alternatives to manage this difficult circumstance [2]. There is a critical need to secure and spare our students, teaching and non-teaching personnel, communities, and the country in general. This circumstance tested the academic system over the world and constrained academicians to move to an online method of educating for the time being. Numerous academic organizations that were prior hesitant to change their conventional academic methodology had no alternative but to move gradually to e-teaching and e-learning.

Technological changes are directly associated to effective pedagogical practices. Developments in these aspects have significant relationship on learning and teaching [3], which aided teachers to achieve active participation of learners and adjust to deviant learning and teaching environments [4]. Teachers must consistently adapt to new skills and keep themselves abreast on innovative ways of communicating and interacting with learners and be able to employ suitable pedagogies and technologies [5]. Nevertheless, shifting to a more sophisticated modality that is entirely different from what they comfortably use is a challenging task for teachers as their students expect learning opportunities from them.

Effective teaching, according to Devlin [4], is generally understood to be concerned with students learning. Two 
broadly acknowledged aspects of effective teaching necessitates a set of specific practices and skills [6] and that it satisfies the context requirements in which it happens [4].

On the other hand, research has revealed that students' understanding of learning is a vital element in producing learning outcomes, but they are not limited to this [7]. The other element is the method where students learn a specific activity. Adopting a paradigm shift in managing learning under new normal may have significant impact on achieving students' expected learning outcomes. Several institutions use technology as innovative pedagogical method either through pure digital or blended learning. Blended learning is a blend of face-to-face and digital learning and teaching being employed depending on the nature of learners' readiness on varied learning and teaching interventions. According to Hoffman [8], effectiveness of blended learning depends on different influences that cause challenges which include the capacity of the student and their sustained commitment to utilize the technology. Those students who have problems with the technology may eventually end the learning and consequently result to unsuccessful technological applications. Successful learning process has learners as focal collaborators, thus their personalities and circumstances influence their ability to effectually keep on with the blended learning.

In the Philippines, the government likewise perceives the mounting significance of blended learning as a strategy to prevent the spread of the Covid-19, particularly digital learning. Swift advances in technology have made distance learning simple [9]. Digital learning has become a forthright life saver for education as universities try to prevent the transmission of the virus in the community [10].

According to Cojocariu et al. [11], a large portion of the terms namely, web-based learning, computer-mediated, blended learning, online learning, open learning, PC intervened learning, and so forth, share for all goals and reason, the capacity to employ a computer or gadget associated with an internet, that offers the likelihood to learn from anytime, anywhere, with any means. Web-based learning can be labelled as an instrument that can make the teaching and learning development focused more on students, increasingly creative, and progressively adaptable. Web-based learning is characterized as learning encounters in synchronous or asynchronous conditions with internet access utilizing various gadgets. In these conditions, learners can be anyplace (autonomous) to learn and connect with educators and different students [12]. The synchronous learning condition is organized as learners go to live talks, there are constant connections among teachers and students, and there is a chance of moment feedback. On the other hand, asynchronous learning situations are not appropriately organized. Here, learning content is not accessible as live talks or classes; it is accessible at various learning frameworks and mediums such as games and videos [13]. Prompt response and reaction are impractical under such domain [14]. Synchronous learning can give a ton of chances to social communication [9]. In the midst of this lethal virus, such web-based mediums are required where, (a) online meetings with students is conceivable, (b) conversations with learners can be possible to keep classes natural, (c) web connections are acceptable, (d) addresses are open in cell phones and not simply PCs, (e) plausibility of observing previously recorded talks, and (f) quick feedbacks from learners can be accomplished and tasks can be taken [15].

Online learning becomes more effective with the use of online resources. The internet is a great resource that students use for learning. Reasons include the ease in searching with sites such as Google, or the vast collection of informative videos on YouTube. Open Educational Resources (OERs) are commonly accessed by academicians through the internet in preparing their lessons or conducting research. These resource materials are easily available, openly licensed media, content, and other advanced resources that are valuable for educating, learning, and evaluating just as for research purposes [16]. It can likewise be modified to individual settings, reproduced on demand or utilized in digital presentations, and applied to empower new academic practices [17].

OER are frequently utilized in programs in distance education in supplemental style alongside conventionally copyrighted resources [18]. The term was first authored at UNESCO's 2002 Forum on Open Courseware and assigned learning, educating, and materials for research in any medium that live in the open domain or have been discharged under an open license that allows zero cost admission, use, adjustment and redistribution by others with constrained limitations. Hence, this permits students and educators to remix content in a localized manner [19], to share a variation of kinds and forms of learning resources [20], and to allow the top resources for teaching a particular topic to be all the more effortlessly discovered.

OER can replace traditional course materials in advanced education. Previous investigations confirmed that the use of OER achieves high student and teacher satisfaction, lesser costs, and similar or even better educational outcomes [21].

In summary, the only sources of information within institutions of higher learning are books, lectures and course materials. However, due to the abnormal circumstances brought about by the pandemic, the sources have changed to more open access to information and more online materials being sourced outside of those provided by teachers. This reform most likely will hasten and alter the way teachers are preparing and delivering instruction and the way students are learning.

The objective of this study is to develop a conceptual framework on fostering digital learning and effective teaching through online educational resources that can be used as reference by a state university in the Philippines. 


\subsection{Aim of the Study}

The COVID-19 pandemic is a massive shock especially to a state university in the Philippines where pedagogical and learning modalities are moving towards web-based or digital on unprecedented scale. Revisions of program curricula are in progress, which is responsive to the clarion call for learner-centered instruction following the flexible learning approach. Teachers are required to develop corresponding learning materials making use of reliable, reputable and recently published references. Unfortunately, some of these resources are not available in the library. Recently procured library holdings however are limited in number which only few teachers may use. Additional burden is the safety measures being enforced by the university administrators that order strict compliance with health protocols, particularly the observance of physical distancing and prohibiting teachers aged 60 and above to report in the school as they are susceptible to health hazards. This prevents them from gaining access to limited university library holdings. The only way for them to accomplish their job is to resort to searching available educational resources online. However, the overarching question is: Do they (the teachers) know how to access these online educational resources and their contribution to digital learning and effective teaching?

This concern prompted the researchers to conduct a qualitative research which aimed to develop a concept on fostering digital learning and effective teaching through online resources from the point of views of faculty members and students of a state university in the Philippines.

Specifically, the researchers were guided by the following questions: What are the perceptions of teachers and students about the importance of digital learning? What are their fears or apprehensions about embracing digital learning? And what are their expectations for leveraging online resources in 2020 and beyond?

\section{Method}

The study aimed to develop a concept on fostering digital learning and effective teaching through online resources from the point of views of faculty members and students of a state university in the Philippines. A qualitative method, employing the grounded theory approach, was used in achieving this aim. Egan [22] defined grounded theory as the discovery of new theory, which emerges from the thorough analysis of data. The data gathered were analyzed through inductive content analysis. Inductive case analysis is examining specific facts which can provide general conclusions.

The purposive sampling technique was used in this study. To obtain in-depth information, twenty (20) participants were chosen from the different academic units of the university. Ten (10) were faculty members who had been teaching for at least 5 years and ten (10) students who are at least on their second collegiate year level.

The instruments used in this study were open-ended questionnaire and unstructured interview. The questionnaire was made by the researcher and was checked and validated by four experts in qualitative research. The open-ended questionnaire was employed so that the respondents can easily express their opinions. In order to supplement the data provided in questionnaires, an unstructured interview was also employed. The unstructured interview was used to gain additional information and can provide explanation to some responses which needs justification.

When the research problem was established, reviews of the related literature were the initial step done by the researcher in order to identify the data of interest which will be used in the development of the questionnaire. The questionnaire was developed with the help of some experts in research. It was also duly checked and validated.

The researchers discussed the objective of the study to the selected participants. The questionnaires were distributed to the selected participants and personally retrieved by the researchers. Upon the retrieval of data, the researcher also conducted an unstructured interview to some of the participants. Five from the ten faculty members and five from the ten students were interviewed through casual conversation. A saturation point of their responses was reached, so the researcher did not interview the other participants. The data gathered were transcribed and subjected for content analysis.

According to Hall [23], inductive content analysis is used in qualitative research, which is carried out through by analyzing raw information from documents, printed and recorded or verbal material, in which based on these data a new theory will be generated. The initial step used in the content analysis is coding and identifying of key terms and concepts of the transcribed data. The identified key terms were seen to appear frequently to the responses of the participants, which were also considered meaningful and important. The second step undertaken in analyzing the data was developing the themes by means of classifying the key terms into categories. After categorizing each theme, comparative analysis was done. By means of comparing the themes, the common grounds were identified. During this process, some of the initial categories were changed, merged or omitted.

In the process of writing the narrative report, data were synthesized, explained and clarified. Cited studies were also used as a basis of understanding developed concepts. The responses of the participants were quoted in original sentences to further support the developed concepts. The participants were coded with $F$ to label the faculty members and $\mathrm{S}$ for the students.

After the explaining and integrating the concepts, which eventually form patterns or relationships, a detailed conceptual framework was made which served as the 
model for fostering digital learning and effective teaching through online resources in a state university.

\section{Findings and Discussion}

The results of the study were presented according to the following sub-topics: perception about the Importance of digital learning for the teacher or student, fears or apprehensions about embracing digital learning, and expectations for leveraging (or using to maximum advantage) online resources in 2020 and beyond. Various views were expressed by the participants regarding the questions asked.

\subsection{Perception about the Importance of Digital Learning for the Teachers and Students}

Faculty and students have toning views about the importance of digital learning as a major teaching and learning modality under the new normal education system. The sudden outbreak of the Covid-19 forced the academic institutions worldwide to shift to an online mode of teaching and learning overnight. As is described by Rieley [24], academic institutions are battling to discover alternatives to manage this difficult situation. These conditions cause us to understand that scenario planning is a critical requirement for educational units.

Digital or Online Learning is a Necessity under New Normal Epoch. The effect of the serious outbreak of this global pandemic Covid-19 can be observed in all levels of educational system, be it public or private institutions. Shifting from offline mode to online mode is considered the panacea for the crisis. The school administrators have crafted an intervention plan to prepare the faculty to outstrip the challenges of online instruction and to make them fully equipped in using digital technology. Members of the academic community, particularly the faculty and students, fully apprehend the need for and importance of shifting to digital learning as indicated by their statements:

"Digital learning will play a vital role at this present situation of health crisis as it will be the only medium made available for the continuity of the learning process not only in school but also between the student and the teachers" (F1)

"It is the most efficient contingency
measure/initiative for us not to stagnate in the
academic realm" (F1)

Digital learning is very important in times like this for it serves as the bridge for continuous education. (F9)

"Although it is a bit difficult for us "nontechy", we have to learn how to use the available digital platforms to give all the lessons that should be taught to the students" (F9)
The overnight shift of teaching and learning modality correspondingly will make the educators change their entire pedagogical approach to adapt to the changing situations and at the same time providing quality education. However, Carey [25] stressed that during this difficult period, the worry is not about whether web-based learning and teaching techniques can give quality instruction but about how educational establishments will have the option to adopt web-based learning in such a huge way.

Accessible and Adaptable System of Education. It is said that online mode of learning is easily accessible and can even reach to rural and remote areas. It is considered to be a relatively cheaper mode of education in terms of the lower cost of transportation, accommodation, and the overall cost of institution-based learning. Flexibility is another interesting aspect of online learning; a learner can schedule or plan their time for completion of courses available online. Combining face-to-face lectures with technology gives rise to blended learning and flipped classrooms; this type of learning environment can increase the learning potential of the students. Students can learn anytime and anywhere, thereby developing new skills in the process leading to life-long learning. The government also recognizes the increasing importance of online learning in this dynamic world [26].

It is mentioned that online method of education is effectively available and can even reach far off areas and regions. It is viewed as a moderately less expensive method of learning as far as the lesser charge of transportation, convenience, and the general expense of school-based education. Adaptability is another intriguing part of web-based learning; a student can plan or schedule their time for fulfillment of courses accessible on the web. Merging face-to-face teaching with online lectures offers ascend to mixed or blended learning; this sort of learning condition can build the learning capability of the learners. Learners can learn anywhere and anytime, along these lines growing new competencies in the process prompting life-long learning. Consequently, the government likewise perceives the expanding significance of web-based learning in this ever-changing world [26].

"Digital learning is adaptable. You can use it whenever, from anyplace and at a pace you like." (S10)

"Can record the lecture and let the students listen to recorded instructions." (F10)

"Also students can be able to identify what they need to learn, find and use online resources." (S1)

"Technology has become advance. You can get any information in just one click" (S9)

Prevention of the Spread of Virus. Studies at Imperial College in London, gauge the worldwide effect in the year 2020 to extend between deaths of twenty million, with 
powerful non-pharmaceutical involvements set up, and deaths of forty million, without such involvements [27].

Investigations in the related literature show the requirement for preparation of nations in the cases of the pandemic toward education. Albeit, bizarrely, students are seen to shield from serious critical contaminations; they can turn into the bases of spread, which was the primary motivation to close the educational institutions around the world [28]. Cakir et al. [29] have given the scientific modeling method that is used in the situation where adequate safeguards are not taken, or precautionary measures are decreased; the direction of the pandemic may show a quick alter in the negative course, so the social distancing must be applied. An investigation by Majumder et al. [30], shows that infection because of contact with the contaminated individual is the most noteworthy option of the spread of Covid-19.

The researchers were able to get the following feedbacks from the teachers and students about how they perceived digital learning as a means to prevent the spread of virus among the students:

"Digital earning is important especially this time of pandemic we are experiencing. If face to face is not possible, we need to appreciate digital learning to avoid spreading the virus" (S1)

"Share knowledge to the students using technology as an effective tool, without compromising both the health of the teachers and the students". (F7)

"Can prevent infection of virus because the session are online" (S4)

"This is the safest way to pursue schooling/teaching during this time of pandemic" (S9)

Learner-Centered Teaching Modality. Web-based learning is perceived to be a student-centered modality where educators are expected to consider a lot of factors that will ensure quality learnings to be acquired by his students. Partlow \& Gibbs [31] asserts that the quality of the courses should be improved continuously and teachers must try their best. This would require a ton of penance and patience on their part and a lot of adjustments to do to deliver their task digitally. As some participants averred:

"Teachers will encounter a lot of difficulty adjusting to the schedule of all his students. He cannot start his session unless majority of his class are present during the online meeting" (F7)

"Digital Learning is pro-students as it makes the learning process easy for them- more convenient, less energy consumption indeed and more conducive" (F8)

"Digital learning is geared toward allowing the learner achieve his education without any barrier of location and access to information." (S3)

"E-Learning is the modern education system. You don't need to attend regular classes." (S5)

"A lot of savings for transportation and meal allowance because I can study at home" (S5)

Web-based learning programs ought to be planned so that they are intuitive, creative, pertinent, and student-focused. Faculty must invest a great deal of time in creating powerful strategies for giving web-based instructions. Viable web-based instructions encourage input from students, make students pose inquiries, and widen the student prospect for the course content [32].

\subsection{Fears and Apprehensions in Using Digital Learning}

The Covid-19 has made organizations to go from offline method to online method of teaching mode. This emergency will make the organizations, which were prior hesitant to change, and to acknowledge present day technology. All educational units must scramble various alternatives of online academic methodologies and attempt to utilize technology all the more suitably. Numerous universities around the globe have completely digitalized their activities understanding the desperate need of this current circumstance. Web-based learning is developing as a victor ludorum in the midst of this pandemic. Thus, the quality improvement of web-based instruction and learning is urgent at this stage [25].

The researchers were able to establish four (4) major concerns that brought fears and apprehensions among teacher and student participants in using digital learning: insufficient knowledge and skills in developing and facilitating e-learning sessions; poor internet bandwidth, unavailability of digital devices for teachers and students and netiquette.

Insufficient knowledge and skills of teachers in developing and facilitating e-learning sessions, as well as low level of students' preparedness. Some participants have accepted their weaknesses in using digital learning brought about by their being digital migrants and lack of knowledge in developing and facilitating e-learning sessions. They mentioned additional concerns, such as:

"Fear of not being able to learn to use the technology effectively" (F4)

"How to use different online platforms to deliver instruction, such as Zoom, Google products, among others" (F10)

"My perception is fifty-fifty... Lack of psychological preparation" (F2)

"Security of the documents as teachers is very important. Virtue of confidentiality must be taken into consideration as well." (F2)

"Different technological innovation in education, I'm also anxious to the manner of teaching that will be adapted soon. No more interpersonal connect 
which is also vital in teaching” (F2).

"Personal human presence adds so much to the learning process, that is why if everything will go digital, I don't think that education will be that holistic which is a primary concern" (F2)

"There is no way for me to know if my students did the reading in an online class". (F6)

On the other hand, readiness of the students to embrace digital learning is another serious concern that requires immediate attention. Since they are used to the traditional face to face interaction with their teachers where they could directly and openly ask questions or clarify vague topics during their discussions, shifting to online learning would definitely throw them out of their comfort zones that will adversely affect their academic performance. Some feedbacks given were:

"Not comfortable watching my teachers discussing over the cellphone. I might be inattentive” (S5)

"Students are not trained on the use of Learning Management Systems” (S8)

"Cheating is possible. Allowing someone to do the assignment for him” (F4)

"Lack of personal interaction with classmates and friends. This will make digital learning a boring session" (S9)

"If everything will go digital, I don't think that education will be that holistic because of poor interpersonal connections with teachers and classmates" (F2)

“Students want two-way interaction ......” (F8)

"There should be interactive learning activities in the e-learning sessions that will provide students opportunities for active engagement" (F5)

"Diversity of students learning needs and styles" (S7)

Consistent with a study, students were not seen to adequately prepar for adjusting their family, work, and social activities with their academic lives in an e-learning condition. Students were likewise seen as inadequately prepared for a few online learning abilities and scholarly-type abilities. Additionally, there is a significantly little readiness among the learners with regards to the utilization of Learning Management Systems [33].

Moreover, web-based learning has such a large amount of flexibility and time that learners never discover time to do it. Individual consideration is likewise a tremendous issue confronting web-based learning. Now and again, online substance is all theoretical and does not allow learners to practice and adapt adequately. Students feel that absence of community, technical issues, and challenges in understanding instructional objectives are the significant barriers for web-based learning [34].

Unavailability of digital tools for teachers and students and Poor Internet Connection. Readiness of the students to embrace digital learning is still dubious because not all of them have the appropriate digital devices to use, such as cellphones or laptops, internet, and Wi-Fi. Dhawan [26] said that inaccessibility of appropriate digital instruments, lack of web or Wi-Fi connections can raise a great deal of trouble because of which numerous students may miss out learning opportunities. Participants have stated their major apprehensions on these:

"Improvement of internet connections" (F1)

"Upgraded gadgets for the teachers and students" (F1)

"Students economic status is next because not everybody can afford to procure and upgrade gadgets from time to time. They should be provided with the needed gadgets" (F3)

Dhawan [26] further stressed that efforts ought to be taken by organizations to guarantee that each student and educator is accessing the necessary resources. They should likewise guarantee that all the instructive applications work on cell phones also, in case learners do not have computer laptops. In this manner, steps must be taken to decrease the online gap.

\subsection{Expectations for Leveraging Online Resources in 2020 and Beyond}

Digital learning is ineffectual if not supported with relevant, reliable and recent scholarly papers and references taken from the available OERs to be used for varied academic and personal undertakings. These online resources are publicly accessible materials for any user to use, re-mix, improve and redistribute under some licenses. The term was first authored at UNESCO's 2002 Forum on Open Courseware and assigned learning, educating, and materials for research in any medium that live in the open domain or have been accessible under an open license that allows zero cost admission, use, adjustment and redistribution by others with constrained limitations. Hence, this permits students and educators to remix content in a localized manner [19], to share a variation of kinds and forms of learning resources [20], and to allow the best resources for teaching a particular topic to be all the more effortlessly discovered. Resources including course materials, textbooks, tests, videos, modules, full courses, and some other instruments, techniques, or methods, were used to help access to information.

Leveraging online resources, as suggested by the participants, can be done by ensuring the highest ethical standard in using online resources or Netiquette and improved internet bandwidth.

Ensuring the highest ethical standard in using online 
resources or Netiquette. One of the common blunders of users of online resources is their failure to follow netiquette rules and standard which violate all rights being enjoyed by the owner of the published materials. However, like many internet phenomena, the concept and its application remain in a state of flux, and vary from community to community. Experiences and observations of participants include:

"Presentation materials are obviously plagiarized as the presenter failed to cite the source of his information" (S5)

"Some research instruments require approval or consent by the author before it can be used or adapted" (F6)

"Some students tend to copy and paste materials taken from online sources without knowing that they already commit plagiarism" (F3)

"Cheating goes with digital learning where (both) the teacher and his students tolerate submission of obviously plagiarized reports" (F9)

Improve Internet Bandwidth. The internet has become a tremendous piece of individuals' everyday live. Through its capacity to act as a medium in various capacities for which individuals use it, the web was acquainted with educational units as an instrument to upgrade student's scholastic involvement with the mid-1990s [35]. In the course of the most recent decades, connectivity on the internet has improved hugely and is accessible wherever, for example, workplaces, homes, and schools [36]. Nevertheless, efficiency of internet service to some areas is getting slow which may adversely affect the application of digital learning and accessing of online materials for academic purposes.

"Internet connection becomes slow due to huge number of users. Even toddlers are contributing to the problem as they are allowed by their parents to watch videos and play online games" (F2)

"Downloading of online resources will be faster if internet connection is good" (S8)

"Internet connection should be speed up at DHVSU so that students and teachers can use the internet more convenient" (S1)

"How can we access online resources for our online teaching if we have intermittent internet connection?" (F5)

This requires improvement of internet bandwidth that will access the full capability of an online learning tool. University officials are currently working on this concern in preparation for the opening of classes this year where blended learning will be employed.

Proper sourcing of online resources. Sourcing OER is a challenging task. Some users found it hard to source appropriate resources for their academic and research undertakings because they are scattered in the internet, and in most cases are openly licensed which requires certain amount to access. Adaptation of online resources likewise necessitates new competencies: to adjust and repurpose OER, the user needs more than fundamental technological capabilities and furthermore needs repetition in remixing and reconsidering resources [18]. Participants shared some of their frustrating experiences, like:

"I could hardly find free scholarly published materials for my lessons..." (F2)

"... not allowed to use Wikipedia for my references.." (S3)

"We should have a list of sites where we could access free online resources" (F6)

Application for Copyright. Another expectation to leverage the use of online resources is the possible intervention on how to assist teachers in applying for copyright that will protect their rights over their original intellectual creations that will be uploaded online. Copyrightable in the Philippines are original intellectual manifestations in the creative and literary domain. These incorporate books, handouts, articles and different works; newspapers and periodicals; lessons, lectures, speeches, papers arranged for oral conveyance such as dissertations; among others. Some statements shared by the participants were as follows:

"My papers to be uploaded will be prone to bootlegging..." (F8)

"The university should extend support for teachers viz-a-viz application for copyrights" (F5)

"Incentives should be given to those teachers with papers or books copyrighted" (F7).

\section{Emerging Concept}

Based on the themes generated from the statements of the participants, the researchers came up with the emerging concept on how to foster digital learning and effective teaching through online resources.

Figure 1 shows the digital learning framework in fostering learning and effective teaching through online resources. Two interconnected boxes were used to present the conjoined relationship between digital learning and online resources. 


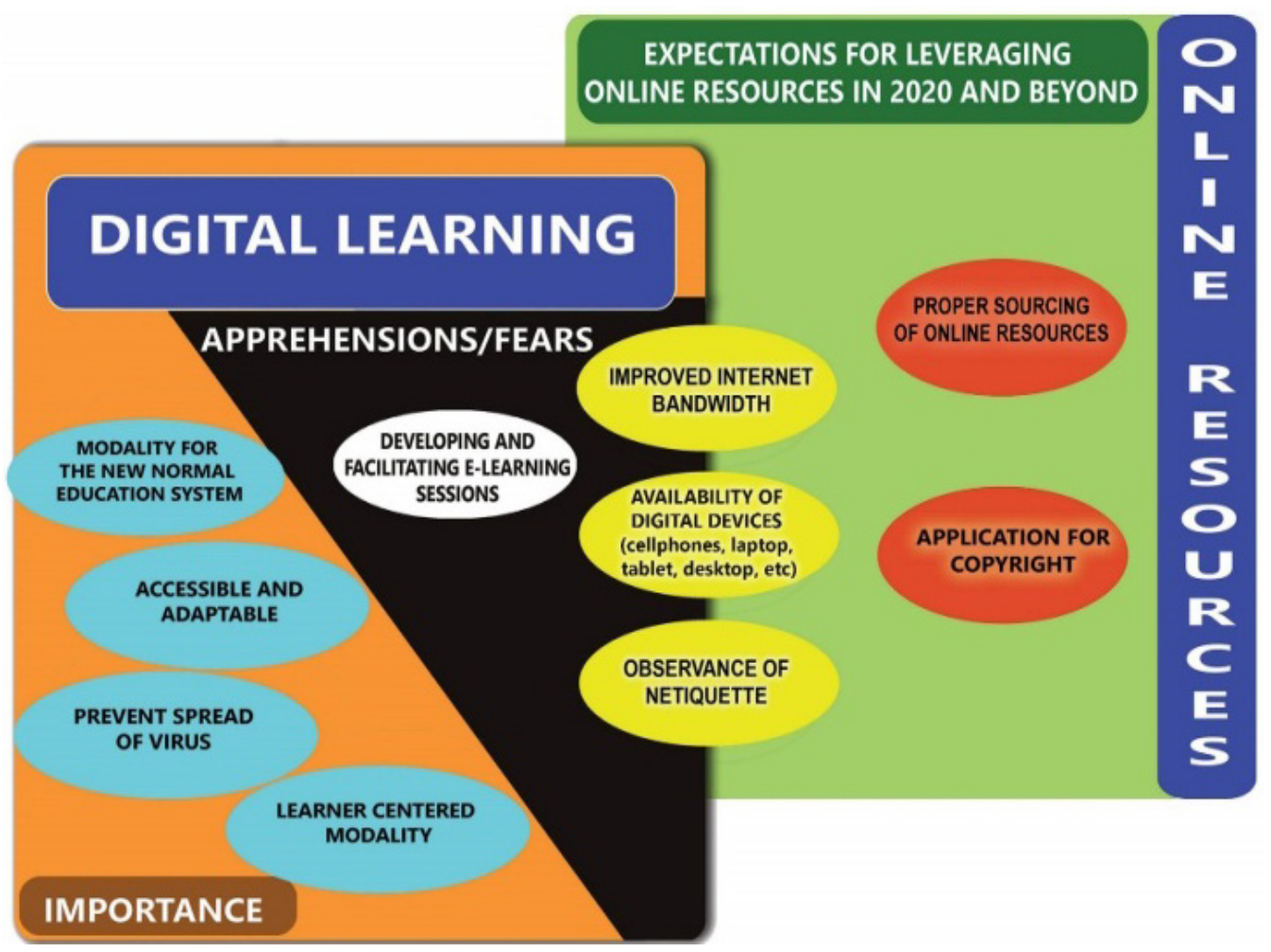

Figure 1. Legamia-Akiate's Framework in Fostering Learning and Effective Teaching Through Online Resources

The Digital Learning Box is divided into two (2) parts with contrasting colors- brown to represent the importance of the online learning and black to represent the apprehensions or fears of faculty members and students in embracing the modality. Four (4) descriptions on the importance of Digital Learning were postulated, such as being a modality for the new normal education system, accessible and adaptable, preventing the spread of virus and as a learner-centered modality.

Conversely, one of the major apprehensions or fears in adapting digital learning is the process on how e-learning sessions will be developed and facilitated. There are three (3) overlapping factors between the Digital Learning Box (particularly under the apprehensions and fears column) and the Online Resources Box which are critical in the effective delivery of digital learning and adverse utilization of available online resources. These include the need to improve the internet bandwidth capacity, availability of digital devices (cellphone, laptop, tablet, desktop, etc.) and netiquette. These factors, together with proper sourcing of online resources and application for copyrights, are expected to be addressed and be made available in order to maximize the use of online resources in 2020 and beyond.

\section{Conclusion}

Based on the conceptual framework which emerged from the study, fostering digital learning and effective teaching through online resources depends mainly on the realization of its faculty members and students that this online mode of teaching is a necessity under new normal epoch, accessible and adaptable system of education, preventing the spread of the virus, and a learner-centered teaching modality.

On the other hand, essential supports need to be provided to eliminate both the faculty and students' fears and apprehensions in embracing the system, which include insufficient knowledge and skills of faculty members in developing and facilitating e-learning sessions, as well as low level of students' preparedness, unavailability of digital tools for teachers and students, and poor internet connection.

On leveraging online resources, faculty and students must ensure the highest ethical standard in using online resources or netiquette, internet providers to improve internet bandwidth, students to properly cite online resources, and application of educators for copyright.

\section{Recommendation}

Based on the conclusions drawn from the study, the researchers therefore recommend the university officials to seriously consider the developed conceptual framework which contains all the essential elements in fostering digital learning and effective teaching through online resources. 


\section{Acknowledgements}

The researchers express their great gratitude to Don Honorio Ventura State University administration, faculty, and students for their support which comprised of direction and input contribution to the needed data for the conduct of the research.

\section{REFERENCES}

[1] Mahase E, Covid-19: WHO declares pandemic because of "alarming levels" of spread, severity, and inaction, Online available from https://www.bmj.com/content/368/bmj.m 1036

[2] C. M. Toquero, Challenges and Opportunities for Higher Education amid the COVID-19 Pandemic: The Philippine Context, Pedagogical Research, Vol.5, No.4, 2020

[3] A. Hannan, H. Silver, Innovating in Higher Education: Teaching, Learning and Institutional Cultures, Buckingham: Open University Press, 2000.

[4] M. Devlin, Improving teaching in tertiary education: Institutional and individual influences. Keynote address at Excellence in Education and Training Convention, Singapore Polytechnic, Singapore, 2007a.

[5] R. Benson, G. Samarawickrema, Addressing the context of e-learning using transactional distance theory to inform design, Distance Education, Vol.30, No.1, 5-22, 2009.

[6] A. R. Penny, Changing the agenda for research into students' views about university teaching: Four shortcomings of SRT research, Teaching in Higher Education, Vol.8, No.3, 399$411,2003$.

[7] P. Ramsden, Learning to teach in higher education, Routledge, London, 1992.

[8] Hofmann J., Solutions to the top 10 challenges of blended learning, Top 10 challenges of blended learning, Online available from cedma-europe.org.

[9] J. L. McBrien, R. Cheng, P. Jones, Virtual Spaces: Employing a Synchronous Online Classroom to Facilitate Student Engagement in Online Learning, The International Review of Research in Open and Distributed Learning, Vol.10, No.3, 2009.

[10] M. P. A. Murphy, COVID-19 and emergency eLearning: Consequences of the securitization of higher education for post-pandemic pedagogy, Contemporary Security Policy, Vol.41, No.3, 492-505, 2020.

[11] V. M. Cojocariu, I. Lazar, V. Nedeff, G. Lazar. SWOT Analysis of E-learning Educational Services from the Perspective of their Beneficiaries. Procedia - Social and Behavioral Sciences, Vol.116, 1999-2003, 2014.

[12] V. Singh, A. Thurman, How Many Ways Can We Define Online Learning? A Systematic Literature Review of Definitions of Online Learning (1988-2018). American Journal of Distance Education, Vol.33, No.4, 289-306, 2019 .
[13] A. Mejia-Downs, J. Gahimer, Pre-planning for Service Learning: Creative Strategies through the Lens of Poverty, Universal Journal of Educational Research, Vol.5, No.10, 1777 - 1781, 2017.

[14] J. Mahoney, C. A. Hall, Exploring Online Learning Through Synchronous and Asynchronous Instructional Methods, Advances in Mobile and Distance Learning, 52-76, 2020.

[15] G. Basilaia, Replacing the Classic Learning Form at Universities as an Immediate Response to the COVID-19 Virus Infection in Georgia, International Journal for Research in Applied Science and Engineering Technology, Vol.8, No.3, 101-108, 2020.

[16] OECD, Giving Knowledge for Free (Summary in English), Giving Knowledge for Free, 2007.

[17] D. Wiley, J. L. Hilton III, S. Ellington, T. Hall, A preliminary examination of the cost savings and learning impacts of using open textbooks in middle and high school science classes, The International Review of Research in Open and Distributed Learning, Vol.13, No.3, 262, 2012.

[18] N. Butcher, M. Wilson-Strydom, Technology and Open Learning: The Potential of Open Education Resources for K-12 Education, International Handbook of Information Technology in Primary and Secondary Education, 725-745, n.d.

[19] S. D'Antoni, Open Educational Resources: reviewing initiatives and issues, Open Learning: The Journal of Open, Distance and e-Learning, Vol.24, No.1, 3-10, 2009.

[20] S. Downes, Models for Sustainable Open Educational Resources, Interdisciplinary Journal of e-Skills and Lifelong Learning, Vol.3, 029-044, 2007.

[21] J. L. Hilton III, L. Fischer, D. Wiley, L. William, Maintaining Momentum Toward Graduation: OER and the Course Throughput Rate, The International Review of Research in Open and Distributed Learning, Vol.17, No.6, 2016.

[22] T. M. Egan, Grounded Theory Research and Theory Building, Advances in Developing Human Resources, Vol.4, No.3, 277-295, 2002.

[23] C. M. Hall, C. M., Quantitative and qualitative content analysis, Handbook of Research Methods for Tourism and Hospitality Management, 395-406, n.d.

[24] Rieley J. B., Coronavirus and its impact on higher education, Online available from https://www.researchgate.net/ post/Corona_Virus_and_its_impact_on_higher_education.

[25] Carey K., Is everybody ready for the big migration to online college? Actually, no. The New York Times, Online available from https://www.nytimes.com

[26] S. Dhawan, Online Learning: A Panacea in the Time of COVID-19 Crisis, Journal of Educational Technology Systems, Vol.49, No.1, 5-22, 2020.

[27] P. G. T. Walker, C. Whittaker, O. J. Watson, The impact of COVID-19 and strategies for mitigation and suppression in low- and middle-income countries, Science, 2020.

[28] A. S. Abdulamir, R. R. Hafidh, The Possible Immunological Pathways for the Variable Immunopathogenesis of COVID - 19 Infections among Healthy Adults, Elderly and Children, Electronic Journal of General Medicine, Vol.17, 
No.4, 2020.

[29] Z. Cakir, H. B. Savas, A Mathematical Modelling Approach in the Spread of the Novel 2019 Coronavirus SARS-CoV-2 (COVID-19) Pandemic, Electronic Journal of General Medicine, Vol.17, No.4, 2020.

[30] P. Majumder, P. Biswas, S. Majumder, Application of New TOPSIS Approach to Identify the Most Significant Risk Factor and Continuous Monitoring of Death of COVID-19, Electronic Journal of General Medicine, Vol.17, No.6, 2020.

[31] K. M. Partlow, W. J. Gibbs, Indicators of constructivist principles in internet-based courses, Journal of Computing in Higher Education, Vol.14, No.2, 68-97, 2003.

[32] M. T. Keeton, Best Online Instructional Practices: Report of Phase I of an Ongoing Study. Online Learning, Vol.8, No.2, 2019.
[33] M. Parkes, S. Stein, C. Reading, Student preparedness for university e-learning environments, The Internet and Higher Education, Vol.25, 1-10, 2015.

[34] L. Song, E. S. Singleton, J. R. Hill, M. H. Koh, Improving online learning: Student perceptions of useful and challenging characteristics, The Internet and Higher Education, Vol.7, No.1, 59-70, 2004.

[35] M. S. Shahibi, K. N. K. K. Rusli, The Influence of Internet Usage on Student's Academic Performance, International Journal of Academic Research in Business and Social Sciences, Vol.7, No.8, 2017.

[36] A. B. Al Fariz, C. A. Lestari, Does Internet Usage Frequency Give Impact to Student's Academic Performance?, Indonesian Journal of Educational Assessment, Vol.3, No.1, $16,2020$. 